\title{
On Exploring a Pervasive Infrastructure to Foster Citizens Participation and Sustainable Development
}

\author{
Catia Prandi \\ Madeira-ITI, \\ ARDITI \\ Funchal, Portugal \\ catia.prandi@m-iti.org
}

\author{
Valentina Nisi \\ Madeira-ITI, \\ U. da Madeira \\ Funchal, Portugal \\ valentina@m-iti.org
}

\author{
Nuno Nunes \\ Madeira-ITI, \\ Tecnico - U. of Lisbon \\ Lisbon, Portugal \\ njn@m-iti.org
}

\begin{abstract}
This paper presents an experimental study where we engaged citizens in a user-driven innovation process to design smart services, exploiting data collected by a low-cost pervasive sensing infrastructure, called Beanstalk. Such as infrastructure has been developed with the final goal to deliver data back to local communities which are empowered to act and leverage the collected hyperlocal information. In doing that, we organized different user-driven innovation sessions aimed to capture communities' ideas and desires, with the intent to develop human centred and transparent intelligent urban environments. The preliminary results show the interest of citizens in being informed about the phenomena revealed by the gathered data and in acting toward a sustainable development, through the creation of smart services.
\end{abstract}

Citizens participation, user-driven innovation, sensing, pervasive infrastructure, smart urban environment

\section{INTRODUCTION}

In 1991, Mark Weiser envisioned an emerging "physical world that is richly and invisibly interwoven with sensors, actuators, displays, and computational elements, embedded seamlessly in the everyday objects of our lives, and connected through a continuous network" (Weiser and Gold, 1999). Nowadays, his vision has become more real than ever, thanks to the wide diffusion of low-cost sensors, and innovative ICT and other pervasive computing technologies (Augusto et al., 2013). In fact, the environment is increasingly becoming more instrumented and interconnected as pervasive sensors and smart devices are generating vast amounts of data (Zaslavsky et al., 2013; Balestrini et al., 2014). The generated data in turns produce new insights and knowledge about the world we live in, that can benefit communities and increase the citizens well-being (Kitchin, 2014; Melis et al.,2016; Prandi et al., 2017a).

In a world where sensing data is becoming inexpensive, the results from data collection and analysis are rarely transparent and open, and even more rarely made available to the communities that the data affects, to act upon. Locals could act and take advantage of this information in a different way than the commercial use and expensive access that big corporations and telecom providers usually grant. Detached from the underlying realities and opportunities these corporations have their own economic interests at heart rather than the wellbeing of the local context, including communities needs and environmental sustainability.

The Beanstalk platform was an experiment in this complex political and cultural context (Nunes et al., 2017). Deployed in a Touristic Island the platform aimed at exploring low-cost passive Wi-Fi sensing to understand the flows of locals and visitors. Unlike many other commercial or institutional ventures based on using Wi-Fi activity to provide mobility analytics, Beanstalk emerged from the collaboration of many stakeholders, including the Tourism Board, small businesses, and communities. Beanstalk is a hardware testbed composed of more than 70 lowcost passive Wi-Fi tracking nodes. The infrastructure spans many touristic points of interest in Madeira Islands with the goal of collecting a large amount of anonymous data to explore spatio-temporal patterns as well as sustainability-related phenomena. In fact, this research is particularly relevant for islands, not only because they are vulnerable to climate change impacts, but also because they provide unique conditions to test complex variables in a controlled environment. In this context, a particular area of interest to investigate is the collection of huge volumes of data to exploit in the creation of smart 
services to foster a sustainable development and improve the citizens' as well as the visitors' wellbeing.

As mentioned previously, we implemented our case study in Madeira, an Atlantic Ocean archipelago, one of the outermost regions of Europe. With 270.000 inhabitants, Madeira attracts more than 1,3 million tourists per year, with a significant impact in the economy (tourism accounts for approximately $20 \%$ of the region's GDP), but also on the environment. To note is that such area accounts for $80 \%$ of the biodiversity of the European continent and provides a unique testbed for testing pervasive technologies for sustainability issues.

With the final goal to deliver data back to local communities which are empowered to act and leverage this information, we decided to included citizens in the process by exploiting user-driven innovation strategies (Buur and Matthews, 2016; Chang and Kaasinen, 2011) as a creative tool to empower locals in design services answering to their actual needs. This paper presents the preliminary outcomes resulting from an exploratory study, emphasizing the relevance to include citizens in the loop of exploiting data and designing services in the context of smart and intelligent environments, toward a sustainable development.

The paper is structured as follows. The next Section will briefly present the Beanstalk pervasive sensing infrastructure. Then, we present the user-driven innovation sessions we performed engaging residents of Madeira. Section 4 describes the resulting insights and challenges emerged from the performed sessions, and, finally, Section 5 concludes the paper.

\section{THE BEANSTALK INFRASTRUCTURE}

Beanstalk allows passive Wi-Fi tracking, exploiting standard low-cost routers used with a modified operating system to collect probe requests from the devices people carry around the deployed node (Nunes et al., 2017). Unlike other commercial systems, Beanstalk doesn't store the IDs of the $\mathrm{Wi}-\mathrm{Fi}$ devices, therefore, protecting the privacy of users. Moreover, each Wi-Fi node is equipped with a low-cost environmental sensors station with the goal of complementing the data gathered through the WiFi tracking infrastructure with data about the urban environment. The additional sensors can measure $\mathrm{CO} 2, \mathrm{CO}, \mathrm{NO} 2, \mathrm{O} 3, \mathrm{SO} 2$, NO, PM 2.5/PM10, noise, temperature, humidity and air pressure.

The Wi-Fi nodes of the Beanstalk infrastructure can gather data in a non-intrusive way, exploring the possibility to provide a wider community of stakeholders with information about sustainabilityrelated issues, such spatio-temporal patterns about the movement of people in tourist destinations, and data related to the air quality and weather conditions (Prandi et al., 2017a). The data gathered by the infrastructure was also used to generate public visualizations (Redin et al., 2017, Prandi et al., 2017b) with the goal of raising awareness about the impact of tourism, in term of mobility flows, and sustainability-related variables (such as $\mathrm{CO} 2$ emissions and energy consumption) in the Island.

In order to deploy our infrastructure, we invited citizens, including people working for public entities and owners of small businesses, such as bars and restaurants, to install our sensors. Through this collaboration, we managed to increase the number of sensed POls to more than 70. Moreover, in collaboration with the main bus company in Funchal (capital city of Madeira), we installed our system in 20 buses, covering three high-frequency routes.

In recent years, different projects tried to deploy a pervasive infrastructure for passive tracking and sensing - see, for examples, (Cunche et al., 2014; Dixon et al., 2013; Sapiezynski et al., 2015), but the Beanstalk infrastructure represents a unique example thanks to its characteristics:

- deployed thanks to the involvement of citizens, across all the Madeira archipelago (i.e., Madeira and Porto Santo islands);

- gathering data about mobility flows (thanks to the passive Wi-Fi tracking) and other urban measures, including air quality;

- using low-cost components (i.e., common routers and low-cost USB sensors);

- still working and collecting huge volumes of data during more than two years.

\section{METHODOLOGY}

With the aim of exploring how to include citizens in the creative process and benefit the local communities through a participatory minded approach, we selected four distinct communities pertaining to four different sites in the island and performed four separate participatory brainstorming sessions mediated by $\mathrm{HCl} /$ interaction designer experts, to capture the communities' ideas and desires.

The four chosen sites and related communities were selected based on capturing diverse communities across the island, preferably not colocated, and making use of the local personal connections and people availability to participate in the workshop. The four sessions were performed in four different Madeiran municipalities and involved different stakeholders:

- Funchal: a class of 2817 year-old students enrolled in the Francisco Franco Secondary School in Funchal; 
- Câmara de Lobos: 5 teachers and 29 students (10-14 year-old) of a school in Câmara de Lobos;

- Calheta: a group of young adults from Calheta;

- Machico: 19 students from different classes of a high school in Machico.

In all the scenarios, the hunt statement that drove the participatory design workshops was:

Creating smart services exploiting the Beanstalk pervasive infrastructure by determining how to use the information to best serve the needs of locals in Madeira.

Each participatory session was organized by a different group of investigators, following a similar process: a brief introduction, the description of the Beanstalk infrastructure, a warm-up exercise, a concept ideation phase in small groups, a mixing ideas activity in larger groups, the presentation of the selected concept. The presentation of the Beanstalk infrastructure and the collected data was crucial to let participants becoming aware of the potential of the system for creating transparent intelligent (urban) environments.

\section{KEY RESULTS}

Participants expressed interest and curiosity in the Beanstalk infrastructure and empowered to explore the collected data for creating services to answer their needs. In fact, different ideas came out during the workshops, inspired by the variety of information available from the system. The resulting concepts were mostly related to the key issues in the Madeira eco-system: nature and biodiversity, sustainability (in terms of energy and air quality), and culture. At the end of each session, guided by the experts, the community selected one main idea as the most interesting and representative of the needs or desires of that specific group. The resulting final four ideas are described as follows.

\section{Funchal}

The selected result from the session in Funchal was a mobile application to monitor air quality and weather conditions through the city of Funchal. The main purpose of such a system is to support users afflicted by asthma and other respiratory issues in walking the city, providing live information regarding most polluted and pollen dense areas. In fact, within Portugal, the island of Madeira has the higher prevalence of asthma: active asthma affects $14.6 \%$, and atopy affects $54 \%$ of the population (Berenguer et al., 2014).

The app would suggest paths that taking into consideration the users' needs and preferences. Figure 1 presents a storyboard expressing the idea behind the designed mobile application.

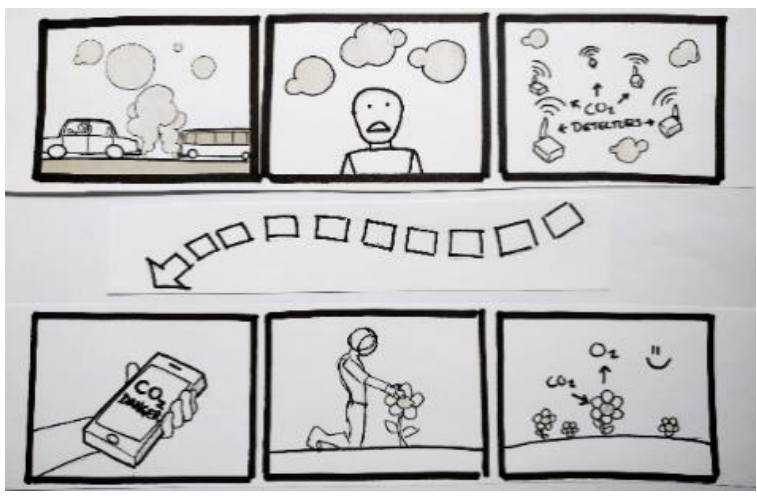

Figure 1: A storyboard presenting the idea behind the mobile app to assist users with respiratory issues.

\section{Camara do Lobos}

A peer-to-peer solar energy market system was the concept resulting from the user-driven innovation workshop in Camera do Lobos. The idea is to enable residents buying and selling renewable energy produced by solar panels on their homes to each other (and directly to businesses). In fact, energy management, and, in particular, storing energy is a open issue in the Madeira island (Miguel et al., 2017). Figure 2 shows two wireframes sketched during the session, visualizing the functionalities that the web-site can provide to manage the energy market.

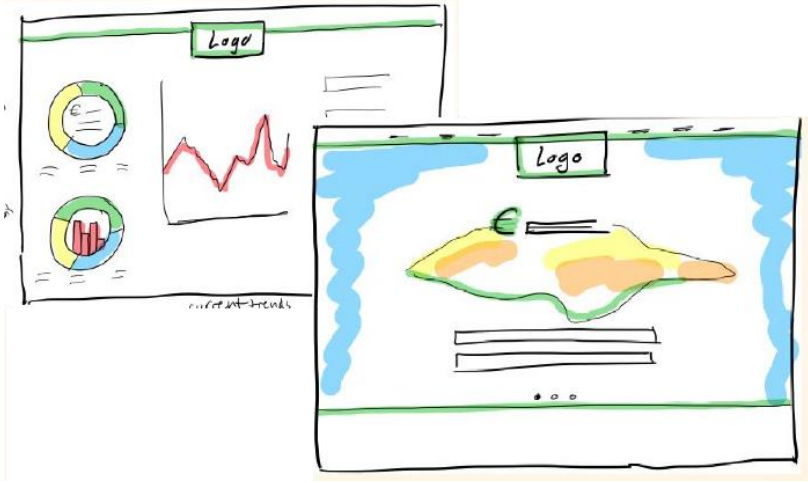

Figure 2: Some wireframes representing the idea of the peer-to-peer solar energy market system.

\section{Machico}

The idea generated by the participants from Machico was related to an open-air museum of Machico history with location-based content and stories that are created and curated by locals that uses the Beanstalk network bus Wi-Fi system as an entry point and enabling technology. The idea is to explore crowdsourcing and users generated content to collect authentic story about such a city, in audio, text or video format. Moreover, anyone will be able to save or share a story that he/she really enjoyed. These two features determine how long the story stays active. Participants also thought to exploit the login functionality exposed by social networks to prevent users to share unappropriated contents and emphasize accountability and sense of community 
among users. Students also proposed to use the transportation system of the island as an advertisement for the stories and call for action for potential curators and storytellers.

\section{Calheta}

The young-adults engaged in the session in Calheta designed a mobile app to assist walkers hiking in Madeira levada walks: historical canals created for irrigation purpose, nowadays popular walking routes across the island that tourists and local use to exercise and to discover Madeiran natural landscapes and rich biodiversity. The app will exploit crowdsourcing and Beanstalk to improve safety alerting users with push notifications about dangerous situations caused by weather hazards such as excess rain, wind or fog, keeping into account weather condition and the local area network (Figure 3 shows a storyboard representing an example of the system usage). The final goal of the application is to reduce the number of accidents while hiking in Madeira that is linear increasing during the last years.

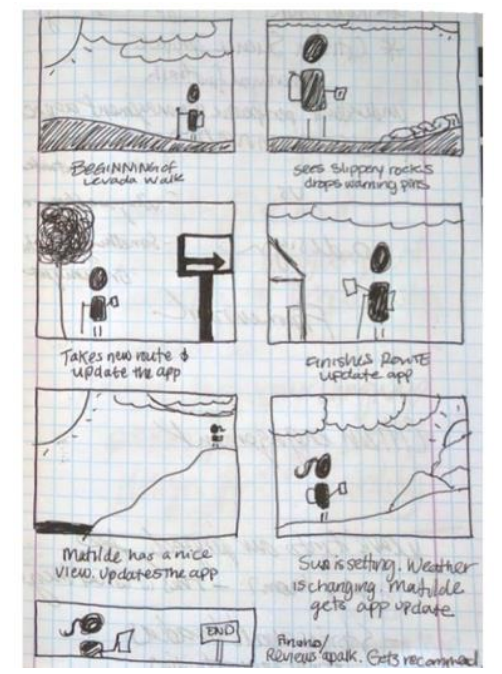

Figure 3: A storyboard representing the use of the app to assist walkers in Madeira.

\section{INSIGHTS AND OPEN CHALLENGES}

The user-driven innovation sessions revealed a substantial creative potential from the local communities as well as the needs and desire to use the infrastructures for locally meaningful purposes. The four ideas that emerged are a testimony of the positive attitude and the creative predisposition of citizens in appropriating the urban pervasive infrastructure and the data it provides. Interesting enough is to notice that all the designed concepts and services are keeping into account the (smart) environment as "providers" of services relevant to the well-being of the Madeira ecosystem. This explorative study allowed us to evaluate the potential of exploiting participatory design over a low-cost pervasive sensing infrastructure (i.e., Beanstalk) to empower citizens in creating services to answer their needs and the sustainability of the island.

In particular, in this context we envision two interesting challenges that need to be better investigated related to citizens participation and appropriation of the infrastructure, to develop usercentred and transparent intelligent urban environments:

(i) Stimulate participation of citizens in order to become providers of data, enlarging the pervasive infrastructure;

(ii) Foster citizens participation to design services exploiting the sensed data toward a sustainable development.

Moreover, considering that Madeira accounts for $80 \%$ of the biodiversity of the European continent, we are also investigating the idea to augment the Beanstalk infrastructure with bio-acoustic sensors for biodiversity monitoring. This scenario opens new challenges and research opportunities, not only considering the area of sustainable $\mathrm{HCl}$ (DiSalvo et al., 2010; Dourish, 2010; Silberman et al., 2014) but also the emerging need of designing smart services in a "more-than human" perspective (Bastian, 2016; DiSalvo et at., 2011; Forlano, 2016).

\section{CONCLUSION AND FUTURE WORK}

We here present an exploratory study involving residents of the Madeira island in user-driven innovation actions aimed to design smart services, exploring the data gathered by the smart urban environment that surround them, created deploying a pervasive sensing infrastructure.

As future work, we intend to better investigate the challenges emerged during the study, engaging a relevant number of residents in a participatory design process with the final aim of proving citizens with smart services, to develop user-centred and transparent intelligent urban environments.

\section{ACKNOWLEDGEMENTS}

We thank all the participants involved in the user-driven innovation workshops, and the $\mathrm{HCl} /$ interaction designer experts who performed the sessions and refined the key concepts (students of the Master of Human-Computer Interaction, Carnegie Mellon Portugal Program). This research was supported by: LARSyS (Projeto Estratégico LA 9 - UID/EEA/50009/2013), MITIExcell (M1420-01-0145-FEDER-000002), and ARDITI H2020MG-2015, CIVITASDESTINATIONS, project n. 689031. 


\section{REFERENCES}

Augusto, J. C., Callaghan, V., Cook, D., Kameas, A., \& Satoh, I., (2013). Intelligent environments: a manifesto. Human-Centric Computing and Information Sciences, 3(1), 12.

Balestrini, M., Diez, T. and Marshall, P., (2014), September. Beyond boundaries: the home as city infrastructure for smart citizens. In Proceedings of the 2014 ACM International Joint Conference on Pervasive and Ubiquitous Computing: Adjunct Publication (pp. 987-990). ACM.

Bastian, M., (2016). Towards a more-than-human participatory research. In Participatory Research in More-than-Human Worlds (pp. 33-51). Routledge.

Berenguer, A.G., Fernandes, A.T., Oliveira, S., Rodrigues, M., Ornelas, P., Romeira, D., Serrão, T., Rosa, A. and Câmara, R., 2014. Genetic polymorphisms and asthma: findings from a case-control study in the Madeira island population. Biological research, 47(1), p.40.

Buur, J. and Matthews, B., (2008). Participatory innovation: a research agenda. In Proceedings of the Tenth Anniversary Conference on Participatory Design 2008 (pp. 186-189). Indiana University.

Coen, M. H., (1998). Design principles for intelligent environments. In $A A A I / I A A I$ (pp. 547-554).

Chang, T.R. and Kaasinen, E., (2011). Three userdriven innovation methods for co-creating cloud services. In IFIP Conference on HumanComputer Interaction (pp. 66-83). Springer, Berlin, Heidelberg.

Cunche, M., Kaafar, M.A. and Boreli, R., 2014. Linking wireless devices using information contained in Wi-Fi probe requests. Pervasive and Mobile Computing, 11, pp.56-69.

DiSalvo, C., Sengers, P. and Brynjarsdóttir, H., (2010), April. Mapping the landscape of sustainable $\mathrm{HCl}$. In Proceedings of the SIGCHI conference on human factors in computing systems (pp. 1975-1984). ACM.

DiSalvo, C. and Lukens, J., 2011. Nonanthropocentrism and the non-human in design: Possibilities for designing new forms of engagement with and through technology. From Social Butterfly to Engaged Citizen Urban Informatics, Social Media, Ubiquitous Computing, and Mobile Technology to Support Citizen Engagement.

Dixon, M., Aiello, S.P., Fapohunda, F. and Goldstein, W., 2013. Detecting mobility patterns in mobile phone data from the Ivory Coast.

Dourish, P., 2010, August. $\mathrm{HCl}$ and environmental sustainability: the politics of design and the design of politics. In Proceedings of the 8th ACM conference on designing interactive systems (pp. 1-10). ACM.

Forlano, L., 2016. Decentering the human in the design of collaborative cities. Design Issues, 32(3), pp.42-54.

Kitchin, R., (2014). The real-time city? Big data and smart urbanism. GeoJournal, 79(1), pp.1-14.

Melis, A., Mirri, S., Prandi, C., Prandini, M., Salomoni, P. and Callegati, F., (2016), September. Crowdsensing for smart mobility through a service-oriented architecture. In Smart Cities Conference (ISC2), 2016 IEEE International (pp. 1-2). IEEE.

Miguel, M., Nogueira, T. and Martins, F., (2017). Energy storage for renewable energy integration: the case of Madeira Island, Portugal. Energy Procedia, 136, pp.251-257.

Nunes, N., Ribeiro, M., Prandi, C., \& Nisi, V., (2017). Beanstalk: a community based passive wi-fi tracking system for analysing tourism dynamics. In Proceedings of the ACM SIGCHI Symposium on Engineering Interactive Computing Systems (pp. 93-98). ACM.

Prandi, C., Nunes, N., Ribeiro, M., Nisi, V., (2017a). Enhancing Sustainable Mobility Awareness by Exploiting Multi-sourced Data: the Case Study of the Madeira Islands. In Proceedings of Fifth IFIP Conference on Sustainable Internet and ICT for Sustainability.

Prandi, C., Chiodo, C., Villaflor, R.J., Autzen, N., Schöning, J., (2017b). The Madeira Touch: Encouraging Visual-Spatial Exploration using a Tactile Interactive Display. In Proceedings of the Doctoral Consortium, Posters and Demos at CHItaly 2017 (pp. 111-115).

Redin, D., Vilela, D., Nunes, N., Ribeiro, M. and Prandi, C., 2017. ViTFlow: a platform to visualize tourists flows in a rich interactive map-based interface. In Proceedings of Fifth IFIP Conference on Sustainable Internet and ICT for Sustainability.

Sapiezynski, P., Stopczynski, A., Gatej, R. and Lehmann, S., (2015). Tracking human mobility using wifi signals. PloS one, 10(7), p.e0130824.

Silberman, M., Nathan, L., Knowles, B., Bendor, R., Clear, A., Håkansson, M., Dillahunt, T. and Mankoff, J., 2014. Next steps for sustainable $\mathrm{HCl}$. interactions, 21(5), pp.66-69.

Weiser, M., Gold, R., 1999. The origins of ubiquitous computing research at PARC in the late 1980s, IBM Systems Journal.

Zaslavsky, A., Perera, C. and Georgakopoulos, D., 2013. Sensing as a service and big data. arXiv preprint arXiv:1301.0159. 